\title{
EVALUATING THE PERFORMANCE OF GLOBAL MODELS APPLYING DYNAMIC ARCHITECTURE
}

\author{
Lamiaa Mohamed Said Mohamed Sherif*, Mohamed Said Meselhy and Sherif El Atar \\ Department of Architecture, Faculty of Engineering, Fayoum University, Fayoum, Egypt. \\ *Corresponding Author E-mail: lamiaa.mihamed@nub.edu.eg
}

\begin{abstract}
Construction Technology has been developed and new technologies have emerged in construction technolog, technics and technology of design technologies have emerged that aim to respond to the user needs, one of the importants is Dynamic Architecture (kinetic), This study presents Dynamic Architecture as one of the leading factors in Architecture. Architecture has evolved from static to dynamic forms, followed by changes in Architectural thought, building materials and methods are developed, computer and multimedia applications in Architecture have been used.

The study is based on an analysis of 5 study models, which is based on the Dynamic Architecture in buildings and reached a set of considerations through which and through the work of a survey, by taking the opinion of a group of specialists and experts in the field of architecture, a measurement ruler for dynamic buildings has been reached and appling to the study models.
\end{abstract}

\section{KEYWORDS: Dynamic Architecture, Kinetic, Building Parts Movement, The Whole Building Movement ,Measuring Ruler}

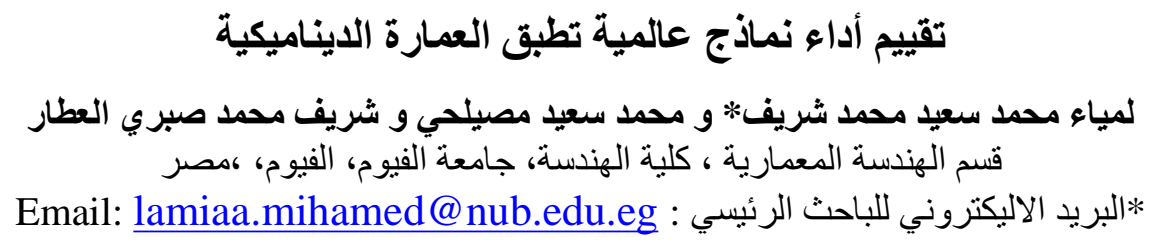




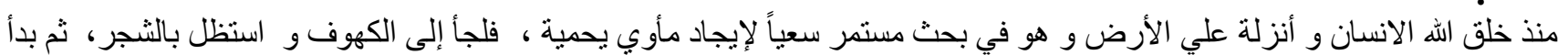

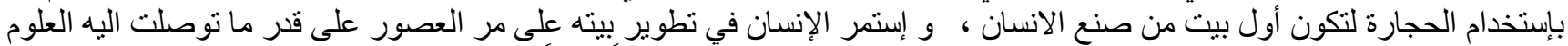

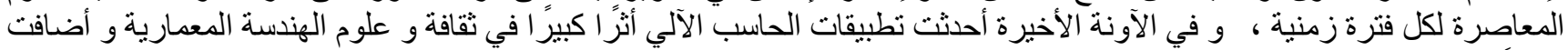

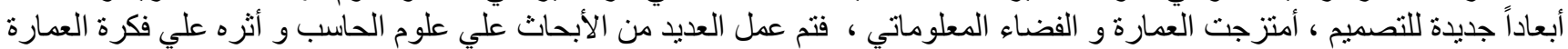

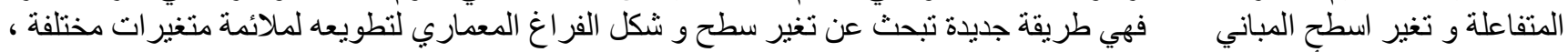
سواء بطريقة طبيعية أو ميكانيكية.

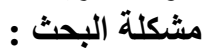

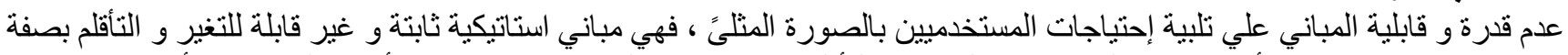

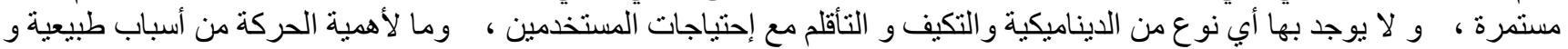

الوصول لمسطرة قياس للمباني الديناميكية عن طريق در اسة مر احل نشأة العمار ة الديناميكية و تحليل لمجمو عة من المباني العالمية تقوم

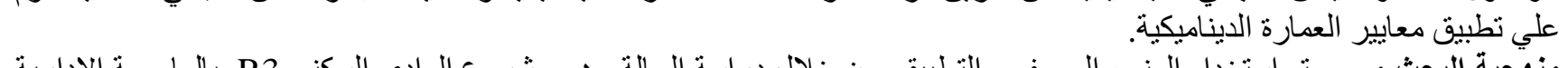

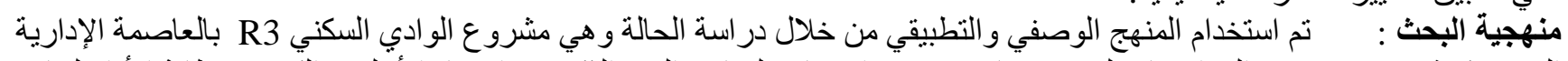

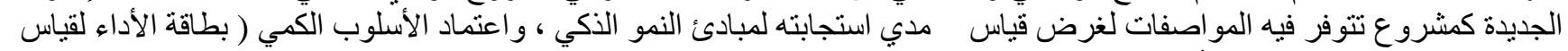

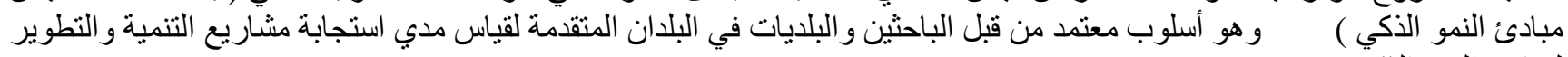
لمبادئ النمو الذكي . يثنتل البحث على ثلاثة محاور أساسية هم المحور الأول: يشتمل على الإطار النظري للبحث (نشأة العمارة الديناميكية)، المحور الثاني:

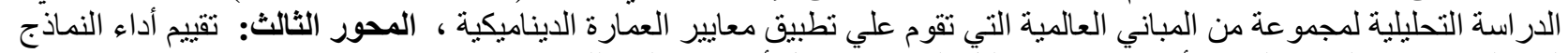

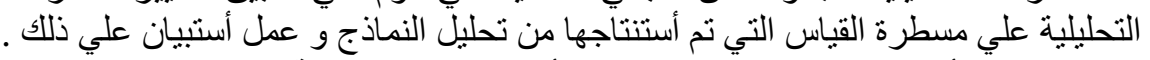

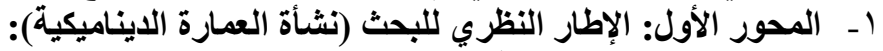

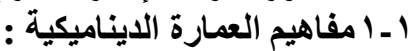

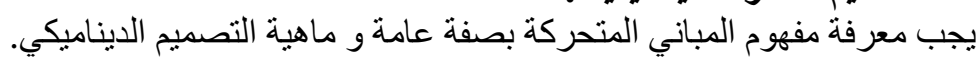

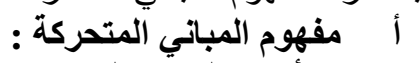

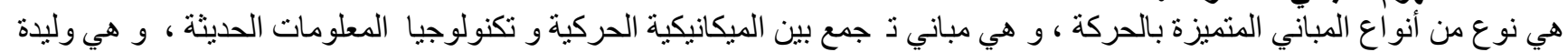

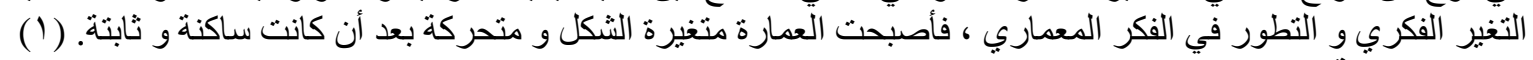

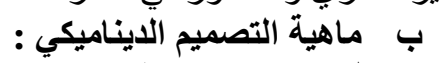

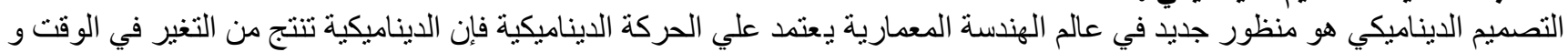

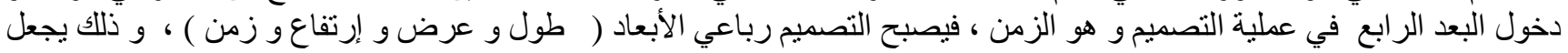

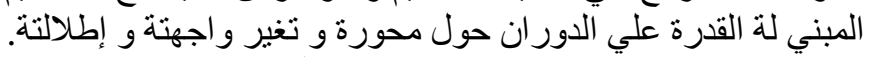

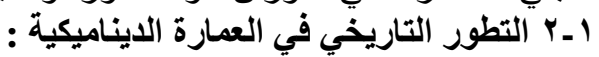

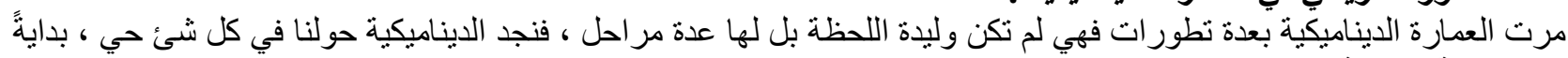

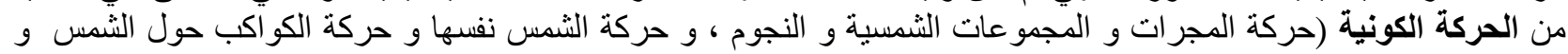

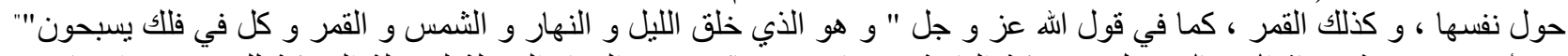

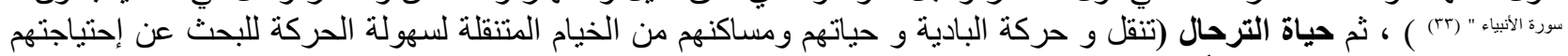

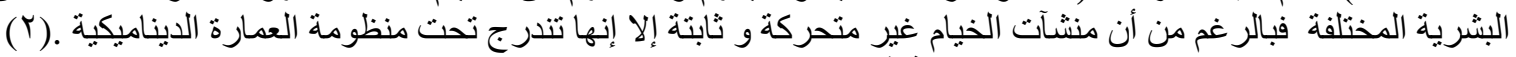

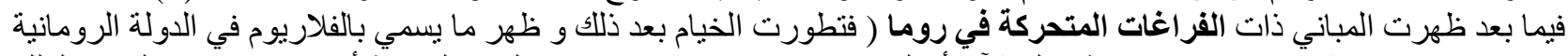

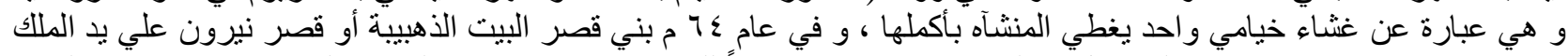

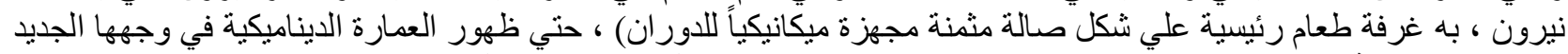

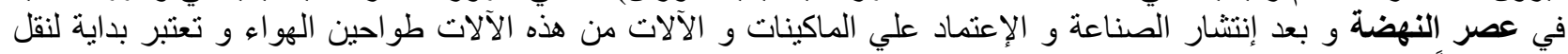

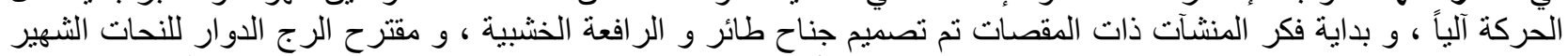

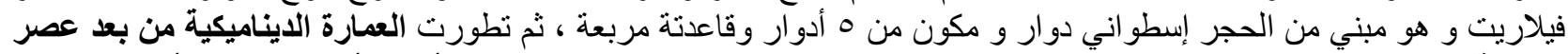

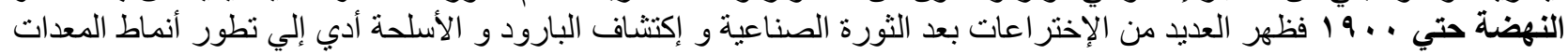

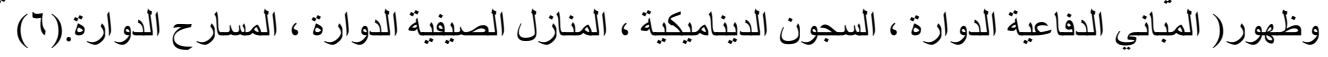




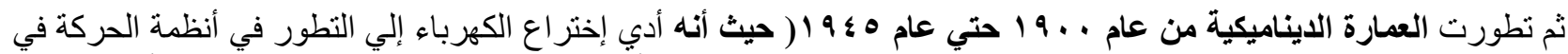

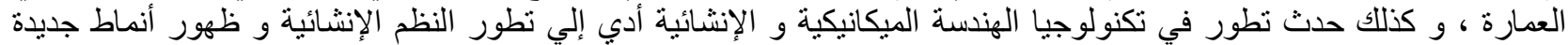
للحركة في المباني.

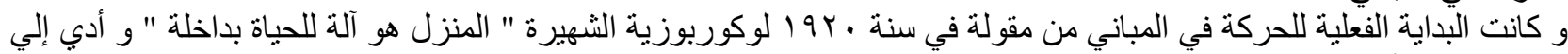

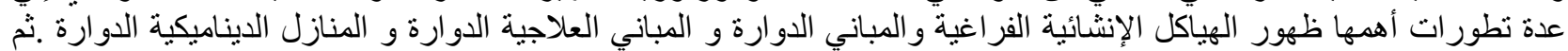

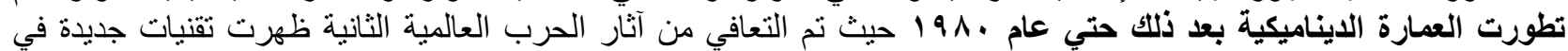

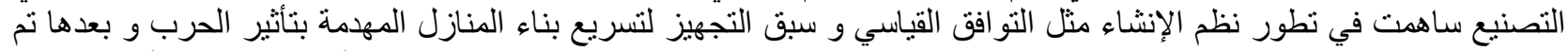

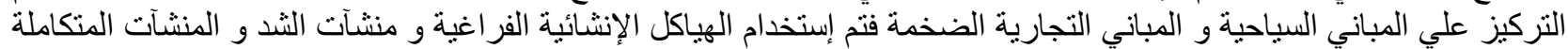

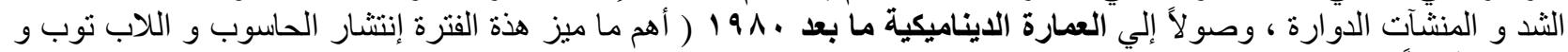

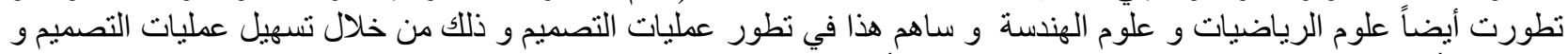

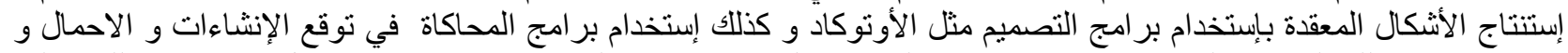

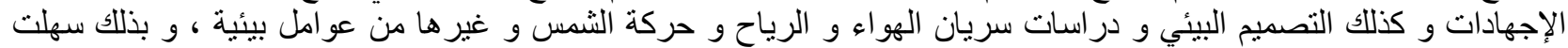
عملية التصميم لتخدم المباني المتحولة ، و تطورت الهندسة الإنثائية و تطور إستخدام المواد فتم إكتثاف المواد الذياد الذكية و مواد

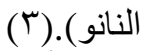

و نجد أن العمارة الديناميكية لم تظهر بصورتها الفعلية و حركة المبني ككل قبل تطبقها في مبني صالة فو لارد بالبرازيل في مدينة

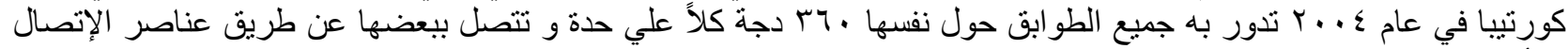

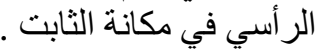

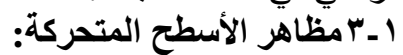

يوجد مجموعة من المظاهر المشتركة في الأسطح المتحركة و يمكن تقسيمها من ناحية التشكيل ، و اللون ، و الحجم ، و الملمس ، و

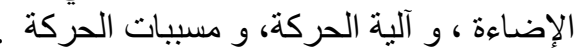

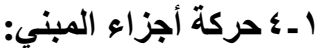

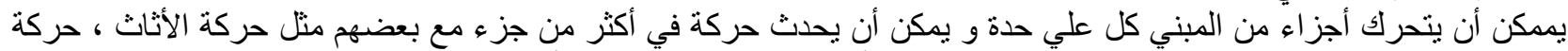

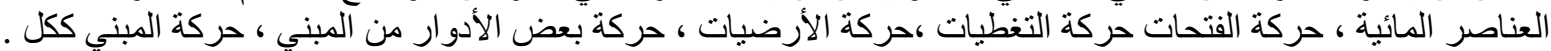

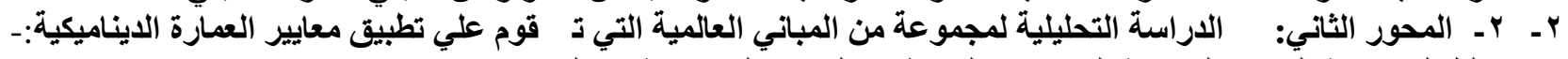

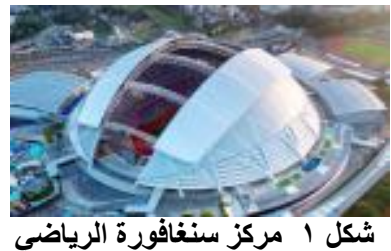

. Singapore Sports Hub المصدر :

https://www.archdaily.com/

523365/singaporeتحليل لمجمو عة النماذج الدراسية التي تقوم علي تطبيق العمارة الدئية الديناميكية في المباني:

r ـ ا إستاد سنغافورة الوطني Singapore National Stadium:

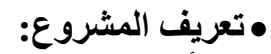

م أسم المشروع : مركز سنغافورة الرياضي Singapore Sports Hub. م موقع المشروع : كالانغ ، سنغافورة.

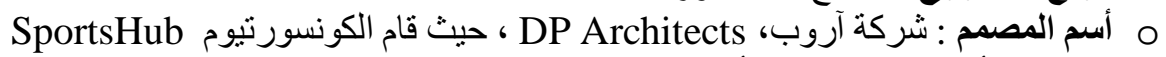

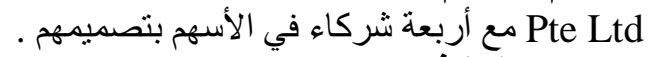

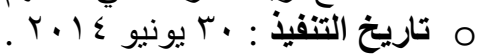

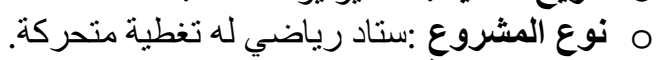
م موضع الحركة : حركة التغطبات.

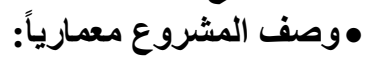

تبلغ مساحته هب هكتار ، ملعب وطني بسعة . . .00 مشجع مع سقف قابل للطي ومقاعد متحركة متعددة المستويات ، و يحتوي

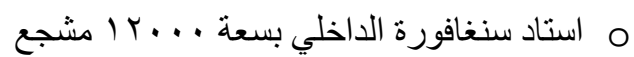

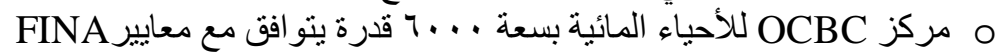

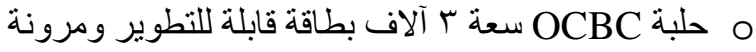
O م يضم مركز الرياضات المائية التجديف و التجديف

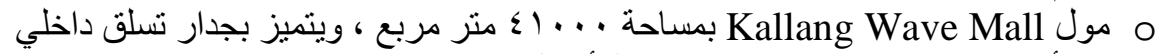

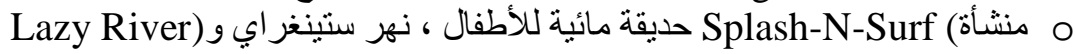
100PLUS الكورنيش الذي يطوق الاستاد الوطني

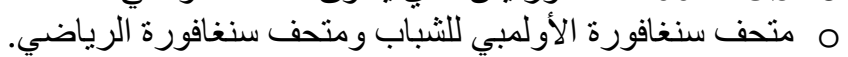

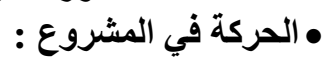




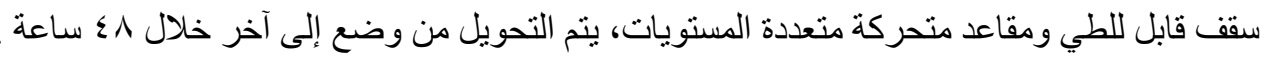

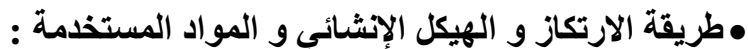

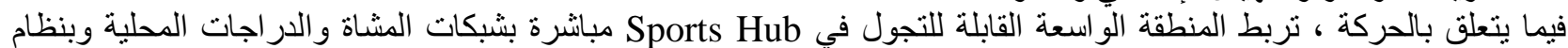

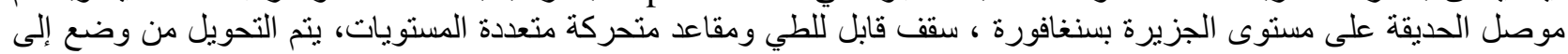

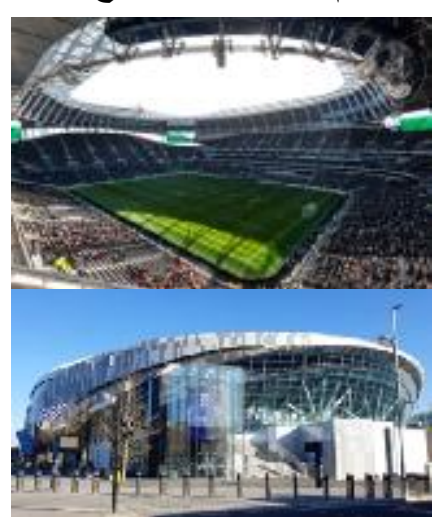

شكل r ملعب Wane Hart Lane

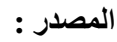

https://www.youtube.com/watc $h ? v=x H L p D p R r Y T w$

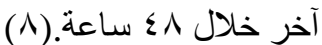

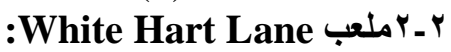

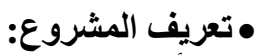

م أسم المشروع : ملعب White Hart Lane الجدوع: الجديد(Spurs'new stadium). O موقع المشروع : نادي توتنهام هوتسبر ، لندن ، إنجلتر ا.

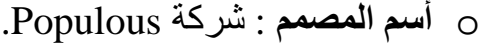

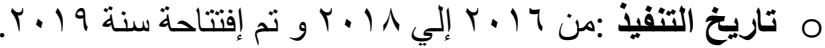

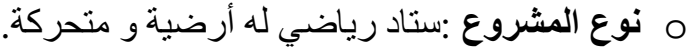
o موضع الحركة : حركة الأرضيات . •وصف المشروع معمارياً:

تم تغطيته بالكسوة المعدنية مثل تلاك المخططة في البداية ، على الرغم من من أنها في شكل محدث

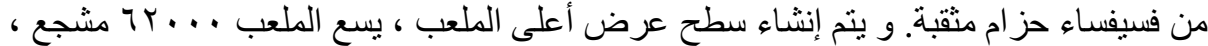

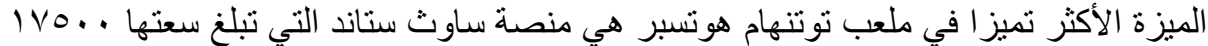

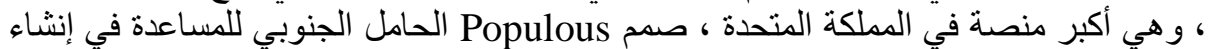

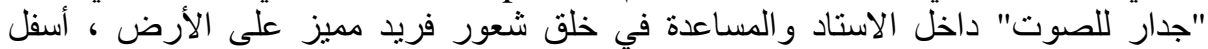

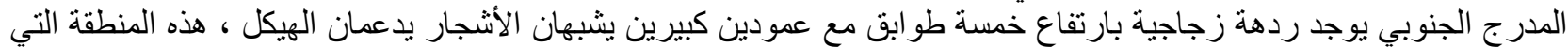

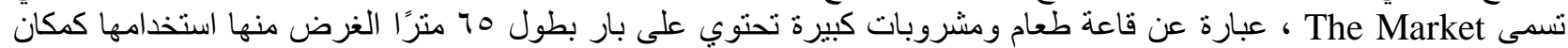

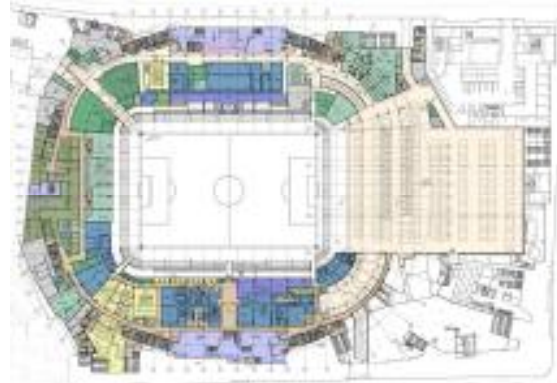

شكل r الحركة في أرضية ملعب White Hart الجديد Lane المصدر :

http://stadiumdb.com/designs/eng/ne w_tottenham_stadium

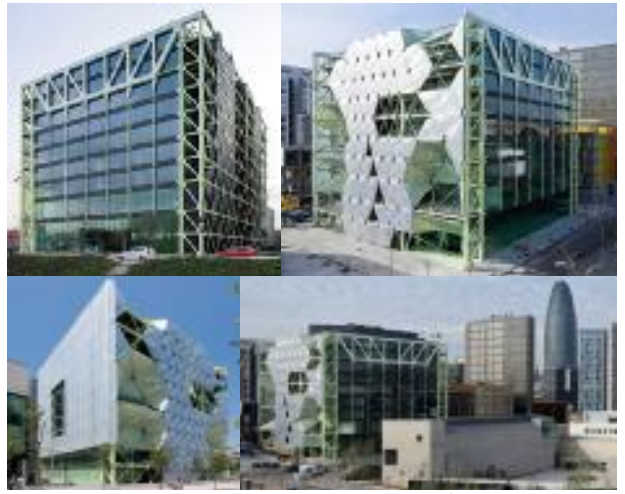

Media Tic Building المصدر :

https://www.archdaily.com/49150/media تجمع قبل وبعد المباريات ، وكذللك يتم فتحها في المناسبات ولمنات المختلفة.

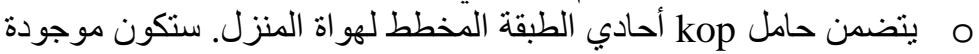
في الجنوب وتحت هذا القسم ، ستكون ميزة جديدة مخفية: تخزين لحقل قابل الحن

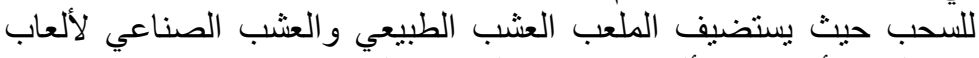

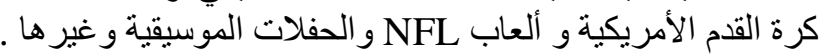

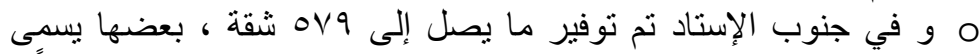

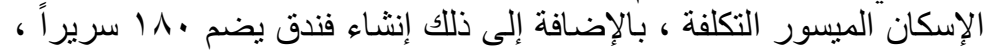
و كذلك مركز صحي . لملى أول ملعب قابل للفصل في العالم ، وسيكون أول

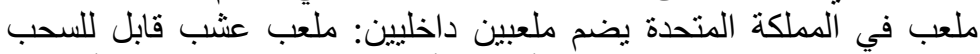
لكرة القدم ، وسطح اصطناعي أسفله لألعاب اتحاد كرة القدم الأمبركي

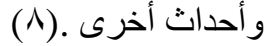

$$
\begin{aligned}
& \text { • الحركة في المشروع : }
\end{aligned}
$$

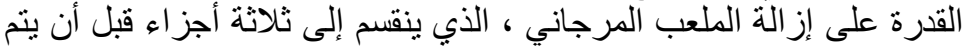

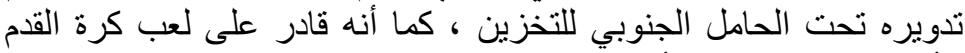

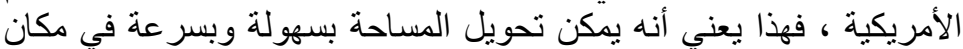

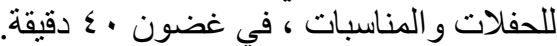

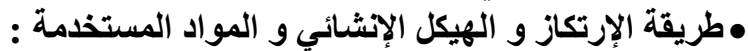

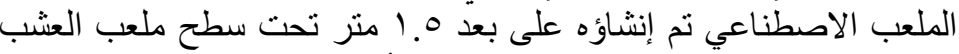

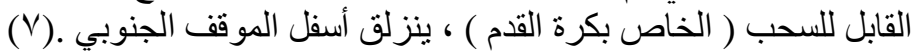

\section{: Media Tic Building $r-r$}

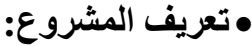

O أسم المشروع : Media Tic Building. o موقع المشروع : برشلونة ، إسبانيا . 


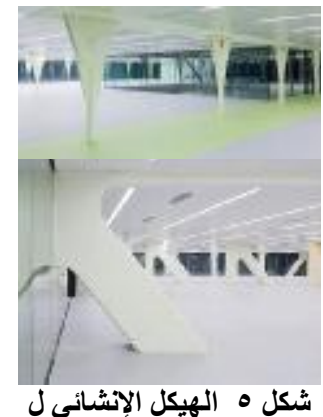

Media Tic Building المصدر :

https://www.archdail y.com/49150/mediatic-enric-ruiz-geli
O أسم المصمم : Cloud 9 Architects.

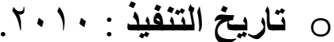

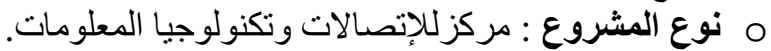
م موضع الحركة : حركة الو اجهات. مركات •وصف المشروع معمارياً:

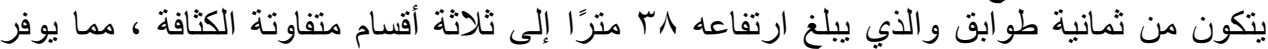

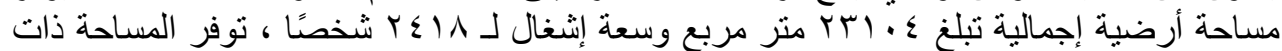

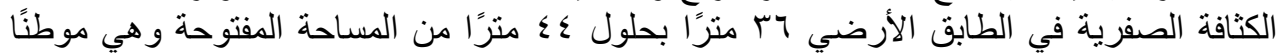

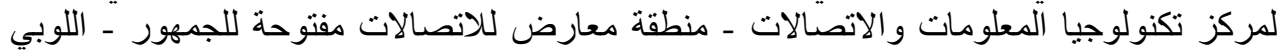

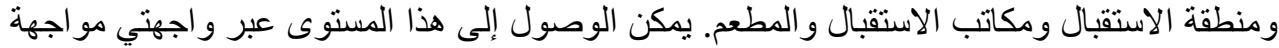

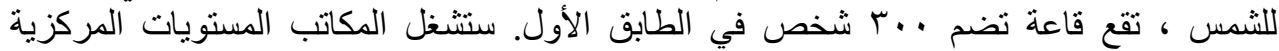

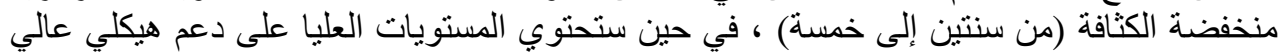

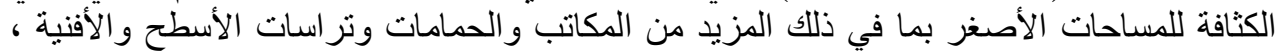

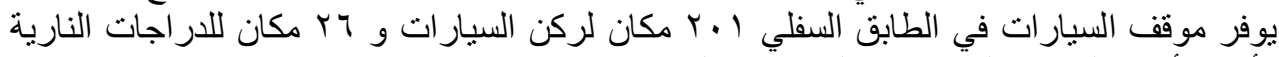

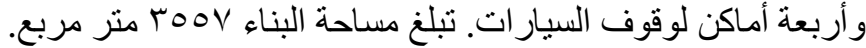

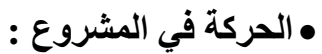

حركة خطية في الو اجهة غير مباشرة بصوة المبرة متورازية و متفاعلة مع البيئة المحيطة.(0)

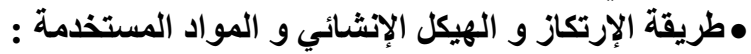

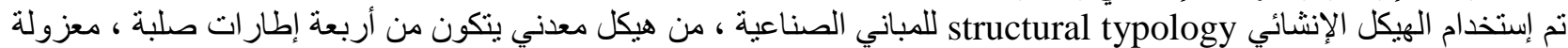

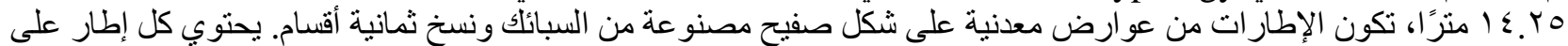

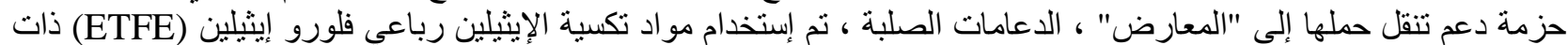

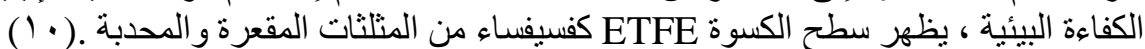

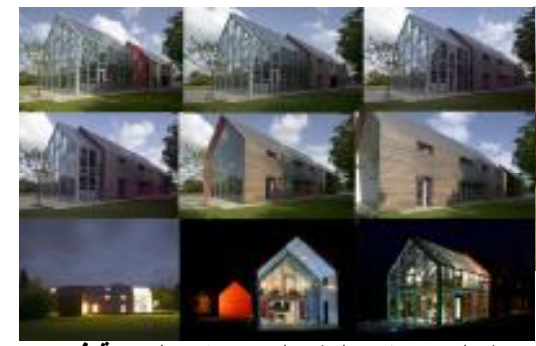

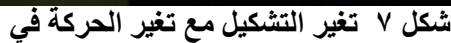

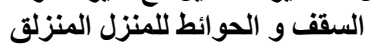
المصدر :

https://www.pinterest.com/pin/4 /38889926167542359

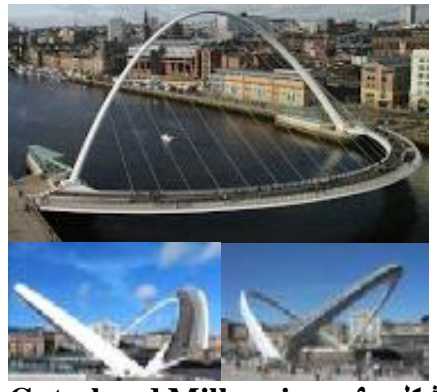

شكل 9 Bridge, Newcastle المصدر :

http://www.lusas.com/case/bri dge/gateshead.html

r- Sliding House البيت المنزئ

\section{• تعريف المشروع: - المثزئ \\ O أسم المشروع : البيت المنزلق}

.House

م موقع المشروع : إنجلتر ا.

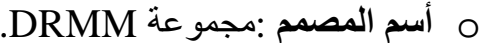
O تاريخ التفيذ :9.9. O نوع المشروع : سكني.

شكل 7 البيت المنزلق Sliding House

المصدر :

https://weburbanist.com/ 2014/08/25/13.

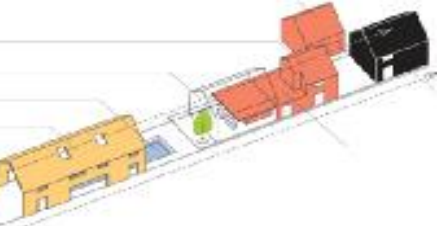

شكل ^ الحركة في المنزل المنزلق المصدر : المنزي

http://drmm.co.uk/projects/view .php?p=sliding-house

\section{•وصف المشروع معمارياً:}

هو منزل ممصم للإستمتاع بالبيئة الريفية مئمارية

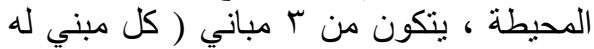

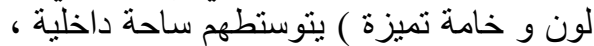

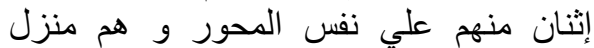
الإعاثة الرئيسي ( من الزجاج ) و جناح الضيوف ( باللون الأسود ) ، و ع علي المحور

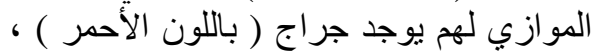
و السقفت و الحوائط المتحركة باللون الخشبي.

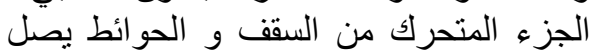

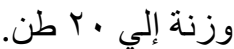

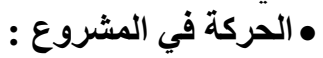

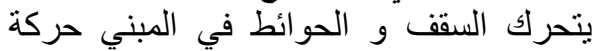
خطية بإستخدام محرك كهربائي مخفي في الحائط ، للإستفادة من أثعة الثمس خلال اليوم . 


\section{تقييم أداء نماذج عالمية تطبق العمارة الديناميكية \\ •طريقة الإرتكاز و الهيكل الإنشائي و المواد المستخدمة :}

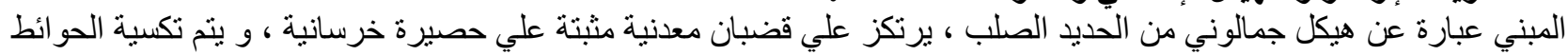

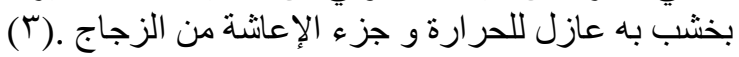

\section{: Gateshead Millennium Bridge, Newcastle كوبري جيتسهيذ ميلينيوم بنيوكاسل

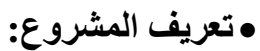

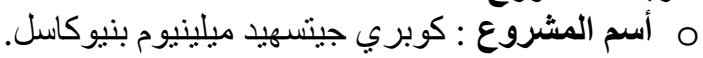

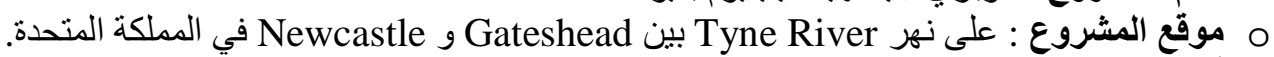

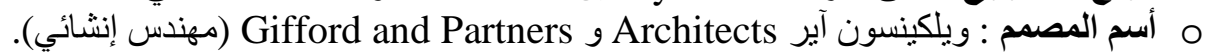

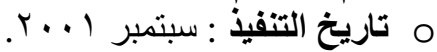

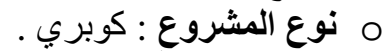
م موضع الحركة : حركة المبني ككل.

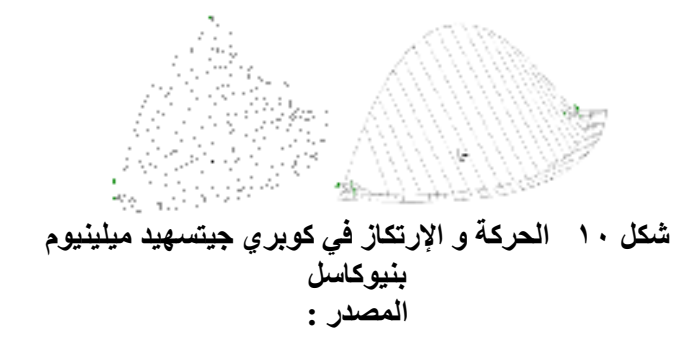

ttp://www.lusas.com/case/bridge/gateshead.html

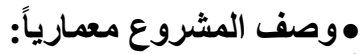

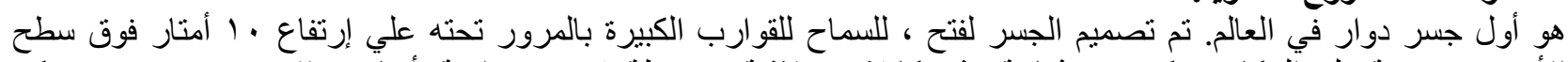

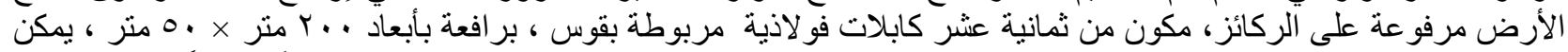

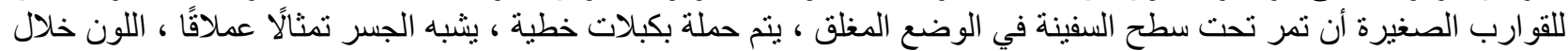

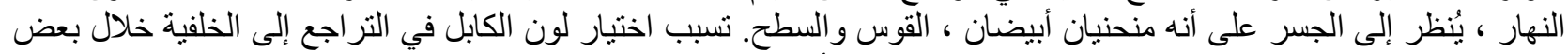

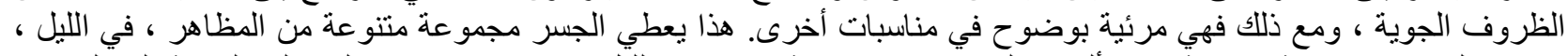

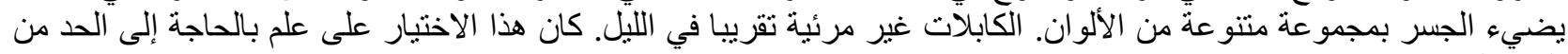

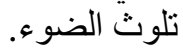

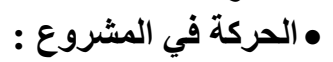

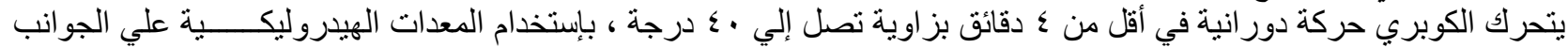

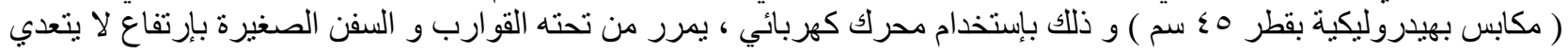

\section{•طريقة الارتكاز والهيكل الإنثائي و المواد المستخدمة :}

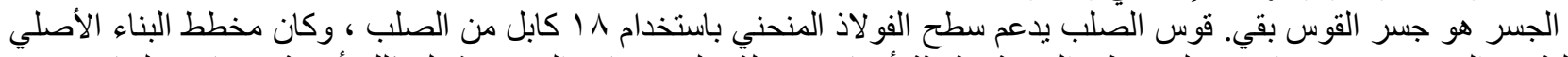

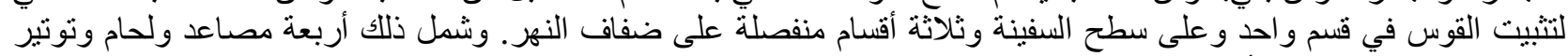

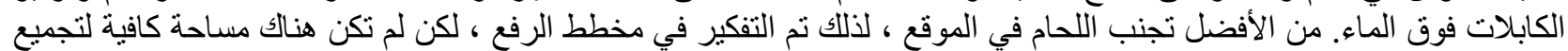

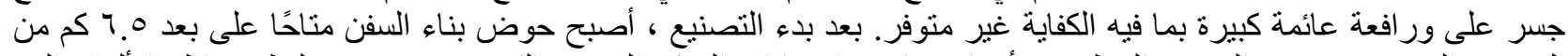

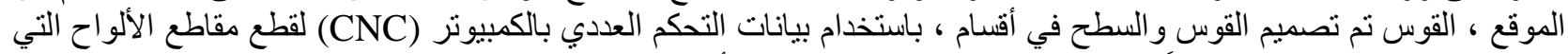

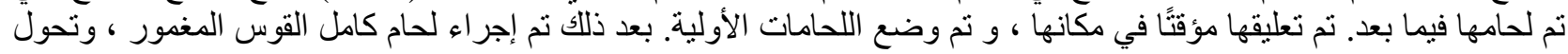

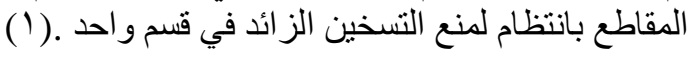

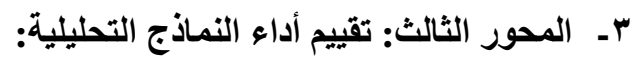

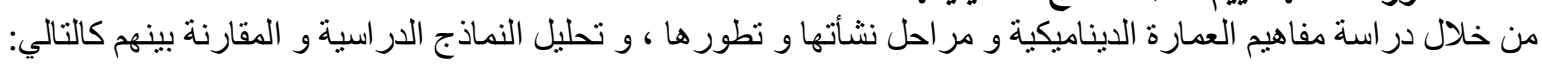


جدول (1) مؤشرات التقييم وفق بطاقة الاداء مقارنة بين النماذج التحليلية المصدر : الباحث

\begin{tabular}{|c|c|c|c|c|c|c|c|c|c|c|c|c|c|c|c|c|c|c|c|c|c|c|c|c|c|c|c|c|c|c|c|c|}
\hline جأقة & إلنتأ| & الطاقة & ـ علي & التأثير & & الكوا & نائي & & تحكم & & مرك & ع الد & & & لـ الد & & & الحرك & رض & & & الحرك & ضع ' & & & ناميك & & & لوطيفيً & عتبارات الـ & & التطليلية \\
\hline 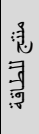 & $\begin{array}{l}2 \\
\text { के } \\
\text { 7. } \\
\text { ज़ }\end{array}$ & 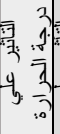 & 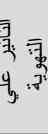 & 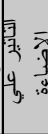 & & 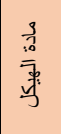 & $\begin{array}{l}\frac{3}{3} \\
-3 \\
-\bar{y} \\
3\end{array}$ & $\begin{array}{l}\frac{3}{y} \\
3 \\
3 \\
3 \\
y\end{array}$ & $\begin{array}{l}\frac{4}{4} \\
\frac{3}{3} \\
3\end{array}$ & 弯. & 紊: & $\begin{array}{l}0 \\
\frac{9}{3} \\
3 \\
3\end{array}$ & $\begin{array}{l}\text { दू: } \\
\text { yे }\end{array}$ & $\begin{array}{l}2 \\
3 \\
.7 \\
.7\end{array}$ & 3. & न. & $\xi_{3}$ & 皇 & 烈 & के & 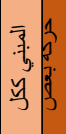 & 方 & $\bar{f}$ & $\overline{3}$ & & $y$ & $\frac{1}{3}$ & $\begin{array}{l}3 \\
\omega \\
\overline{3} \\
\text { s. } \\
\omega \\
\omega\end{array}$ & 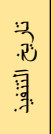 & 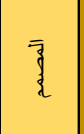 & (2) & $\begin{array}{l}3 \\
3 \\
3\end{array}$ \\
\hline 0 & 0 & 0 & 0 & 0 & 粉 & $\begin{array}{l}\text { 舟. } \\
\text { f. }\end{array}$ & 0 & & OC & 0 & 0 & 0 & 0 & 0 & 0 & 0 & 0 & 0 & ○) & 0 & 0 & 0 & 0 & 10 & & 0 & 0 & رياض & $\stackrel{+}{\sim}$ & \begin{tabular}{|c|} 
Ty \& \\
DP \&
\end{tabular} & |كنغالانغرة : & الوطنافورة \\
\hline 0 & 0 & 0 & 0 & 0 & 畒 & 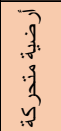 & 0 & 0 & 0 & 0 & 0 & 0 & 0 & 0 & 0 & 0 & 0 & 0 & 0 & 0 & 0 & 0 & 0 & 0 & & 0 & 0 & رياض & $\stackrel{\infty}{\infty}$ & $\begin{array}{c}\text { Popul } \\
\text { ous }\end{array}$ & | لندلترا ، & $\begin{array}{l}\text { White } \\
\text { Wart } \\
\text { Lane }\end{array}$ \\
\hline 0 & 0 & 0 & 0 & 0 & 㞾 & 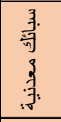 & 0 & & $\mathrm{OC}$ & 0 & 0 & 0 & 0 & 0 & 0 & 0 & 0 & 0 & 0 & 0 & 0 & 0 & 0 & 10 & & 0 & 0 & |لإتصا & ํㅜㄹ & \begin{tabular}{|c|} 
Cloud \\
9 \\
Archit \\
\end{tabular} & | برشلونة & $\begin{array}{l}\text { Media } \\
\text { Tic } \\
\text { Building }\end{array}$ \\
\hline 0 & 0 & 0 & 0 & 0 & $\begin{array}{l}3 \\
3 \\
3 \\
3\end{array}$ & 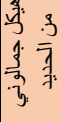 & 0 & & OC & 0 & 0 & 0 & 0 & 0 & O & 0 & 0 & 0 & 0 & 0 & 0 & 0 & 0 & 10 & & 0 & 0 & سكني & : & $\begin{array}{c}\text { DRM } \\
M\end{array}$ & إنجلترا & $\begin{array}{l}\text { المنزل } \\
\text { Sliding } \\
\text { House }\end{array}$ \\
\hline 0 & 0 & 0 & 0 & 0 & $\Phi$ & 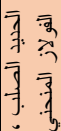 & 0 & & OC & 0 & 0 & 0 & 0 & 0 & 0 & 0 & 0 & 0 & 0 & 0 & 0 & 0 & 0 & 10 & & 0 & 0 & كو بري & $\bar{\sim}$ & | ويلكينسو & المنحدة & بنيتيوكيد كوبيد \\
\hline
\end{tabular}

تم التوصل لمجموعة من الإعتبار ات تم عملي إستيبان للأهية النسبية لكل منهاو توصلنا لمسطرة القياس التالية .

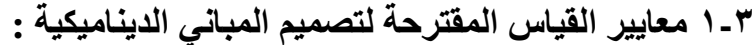

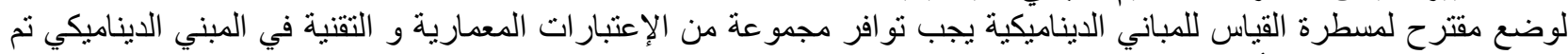

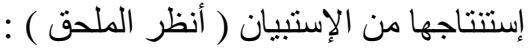

جدول (ץ) مقترح لمسطرة قياس لتصميم المباني الايناميكية المصدر : الباحث

\begin{tabular}{|c|c|c|c|}
\hline \multicolumn{2}{|c|}{ الأهميةة } & نصر التقيبم & و الإعتبارات المعمارية \\
\hline \multirow{7}{*}{ Ү^.V } & r. & إختيار الموقع المناسب & \multirow{7}{*}{ الإعتبارات الوظيفية } \\
\hline & $\varepsilon . \mu$ & توفير جميع الفراغات طبقاً للوظيفة المطلوية في المبني & \\
\hline & $\varepsilon . r$ & التوافق بين التصميم الديناميكي و الإحتياجات الوظيفية للفراغات الداخلية & \\
\hline & $\varepsilon . \varepsilon$ & العلاقة بين الجزء الثابت و المتحركة و عدم إعاقة أي منهما وظيفة الأخر & \\
\hline & $\varepsilon . \varepsilon$ & 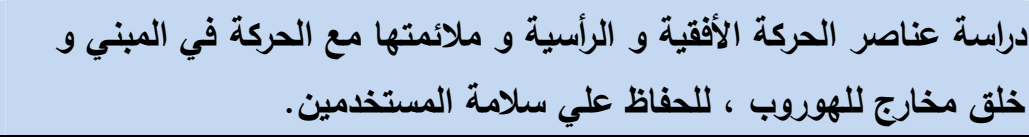 & \\
\hline & r.q & تداخل مضاراتها. الخدات و المرافق في أماكن تخديمها المناسب و مراعاة عدم تكرارها و & \\
\hline & $\varepsilon$. & تطبيق التصميم الديناميكي للوائح و القوانين و التشريعات طبقاً لمكان التنفيذ و & \\
\hline 11.9 & $\varepsilon .1$ & كفاءة التهوية الطبيعية & الإعتبارات البينية \\
\hline
\end{tabular}


تقييم أداء نماذج عالمية تطبق العمارة الديناميكية

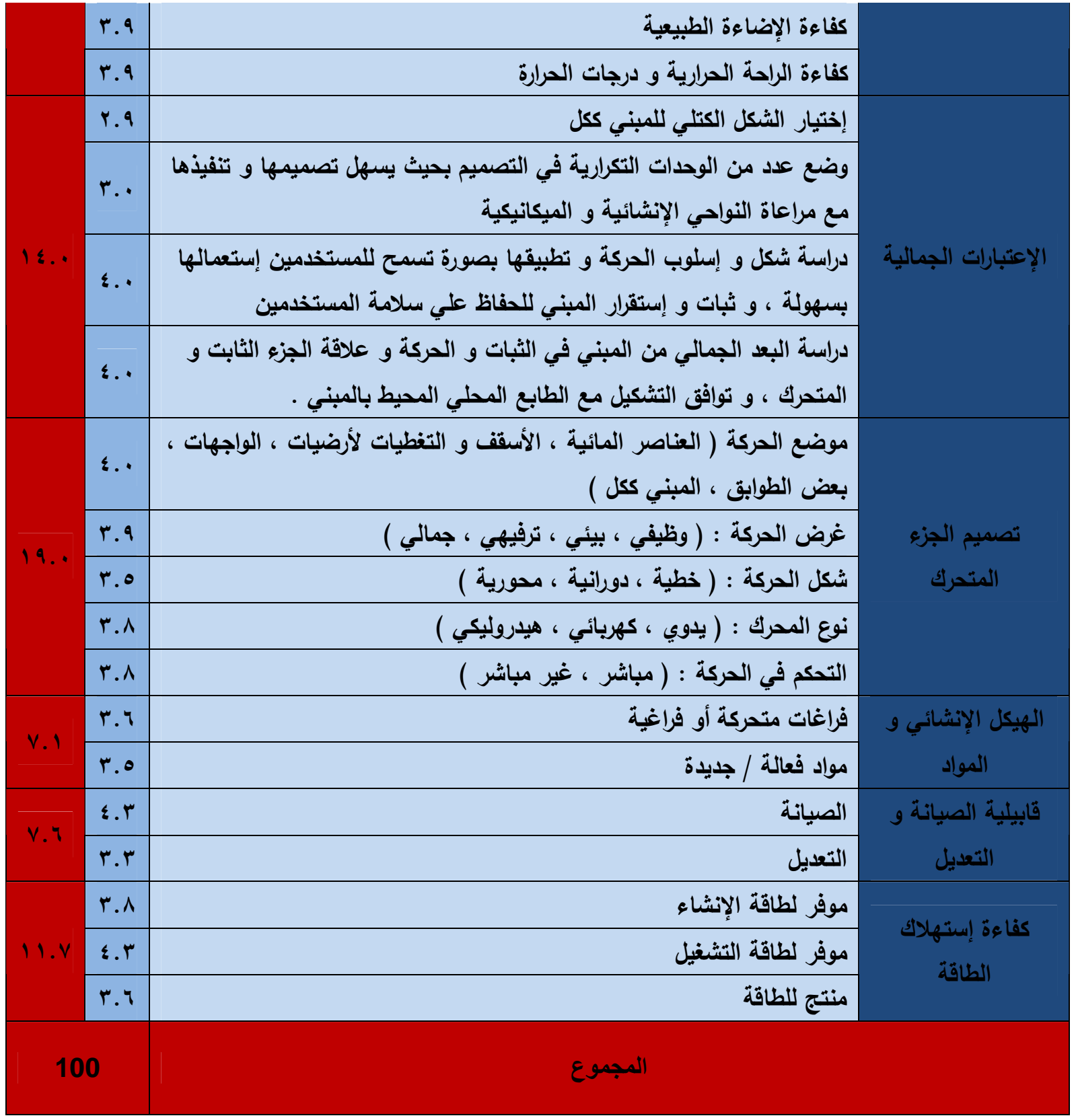

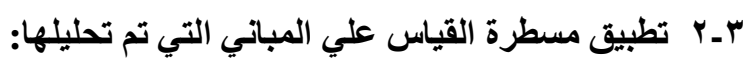


تقييم أداء نماذج عالمية تطبق العمارة الديناميكية

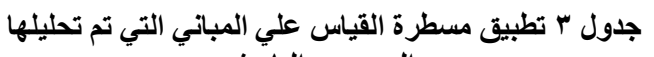

المصدر : الباحث العثر

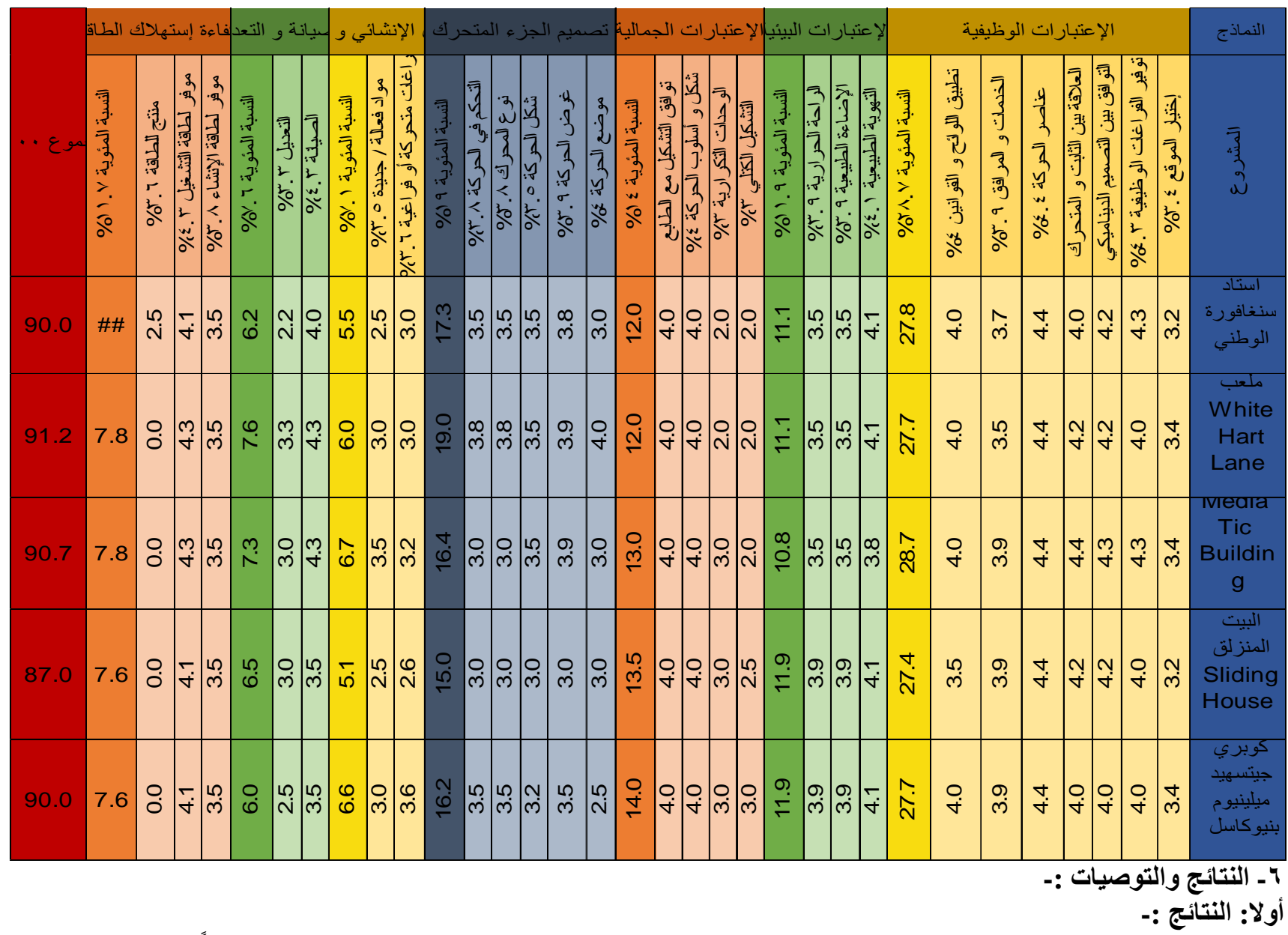

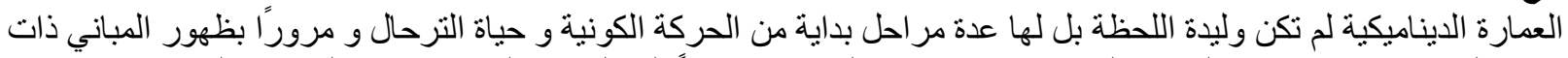

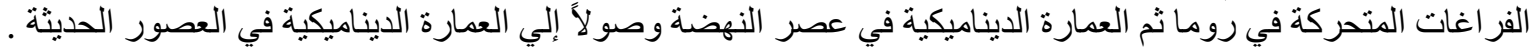

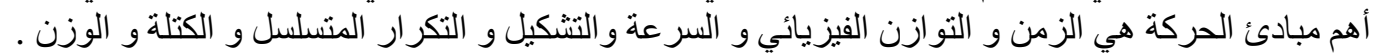

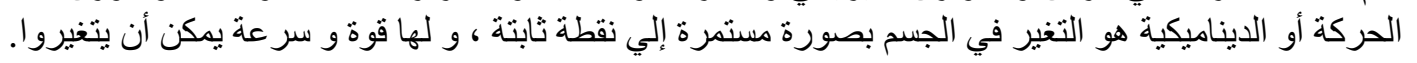

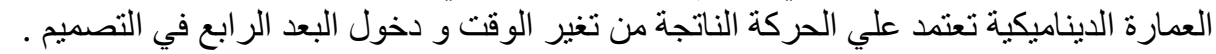

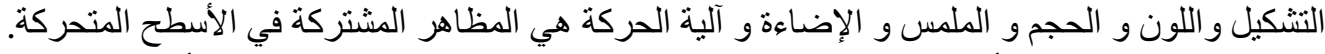

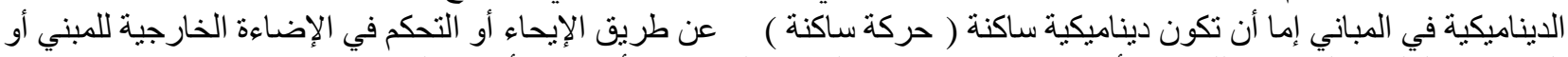

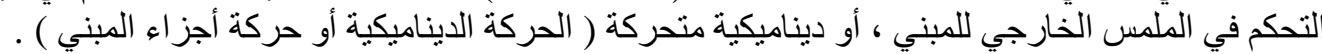

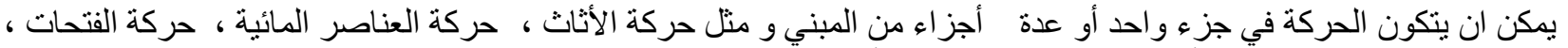

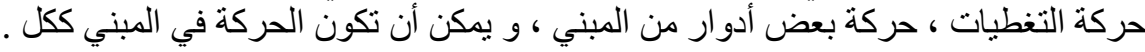

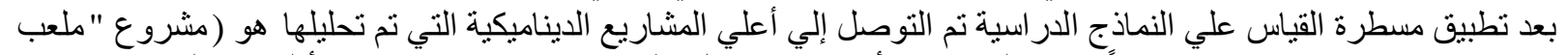
(White Hart Lane

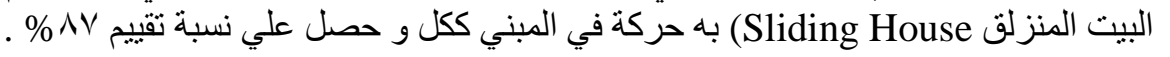


ثاتيا التوصيات :-

ي يجب نشر ثقافة العمارة الديناميكية في جميع الأوساطو ليست الأوساط المعمارية فقط.

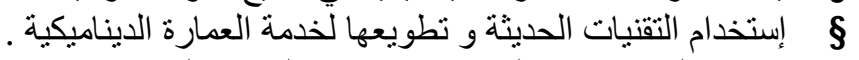

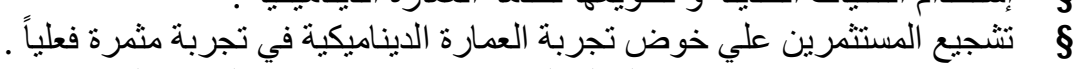

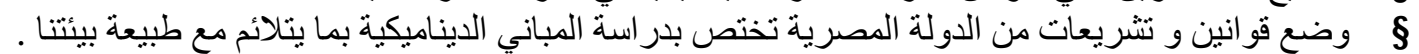

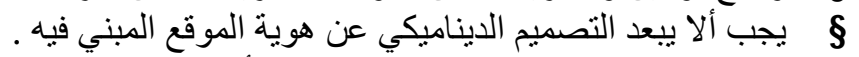

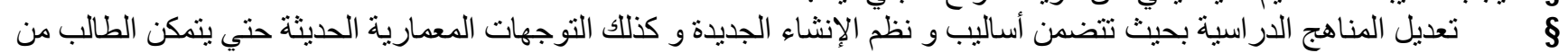

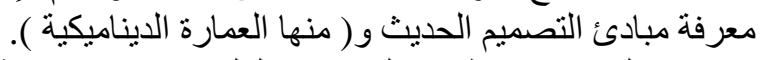

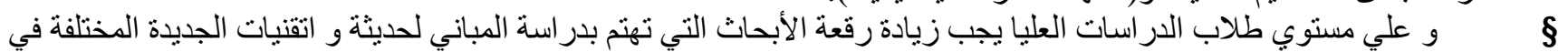

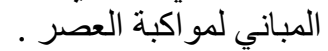

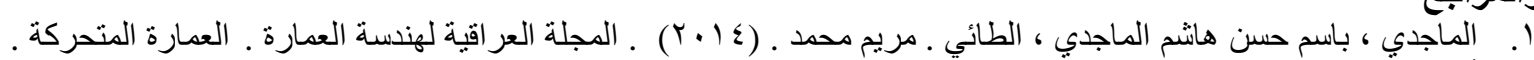

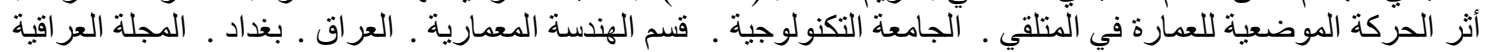

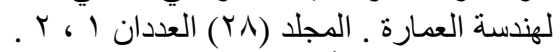

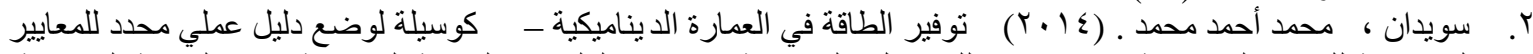

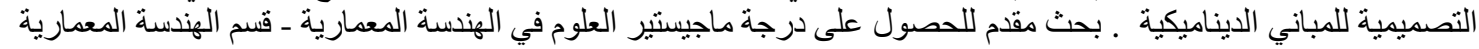

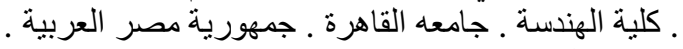

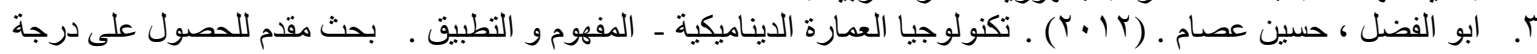

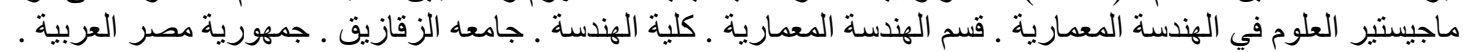

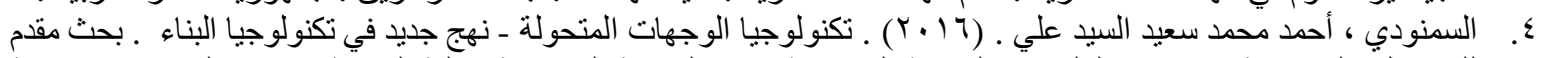

للحصول على درجة ماجيستير العلوم في الهندسة المعمارية ـ قسم الهندسة المعمارية ـ كلية الهندسة ـ جامعه القاهرة ـ جمهورية

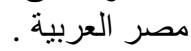

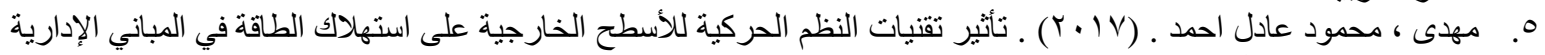

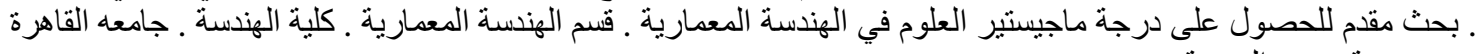

6. Revolving Architecture: A History of Buildings that Rotate, Swivel, and Pivot 1st Edition.

7. www.dezeen.com

8. https://www.archdaily.com/523365/singapore-sportshub-dparchitects , 1/11/2019

9. http://stadiumdb.com/designs/eng/new_tottenham_stadium ,1/11/2019

10. https://www.designbuild-network.com/projects/media-tic/ , 1/11/2019

11. http://www.lusas.com/case/bridge/gateshead.html ,1/11/2019 


\section{ملحق 1 \\ نموذج إستبيان عن العمارة الديناميكية}

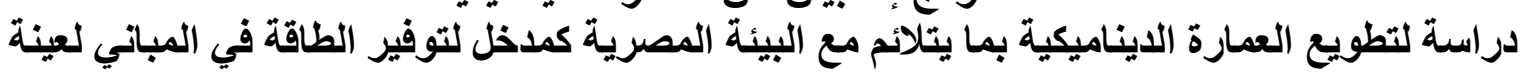

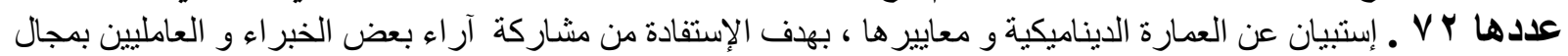

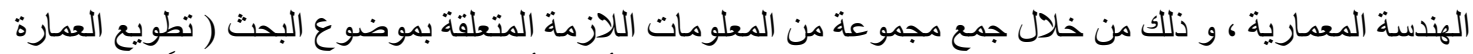

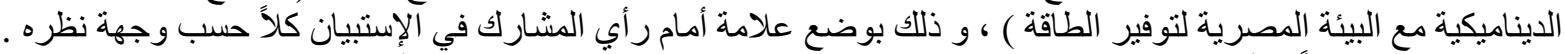

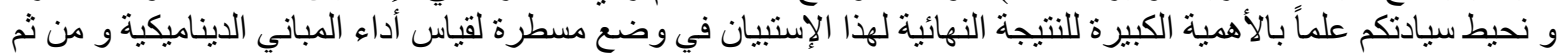

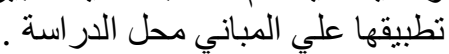

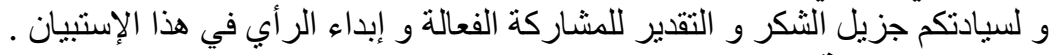

O

\section{كاديمي}

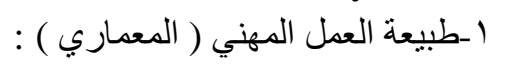

0

$$
\text { هندس حر أو في مكان خاص }
$$

هندس حكومي

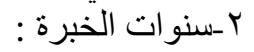

\section{o}

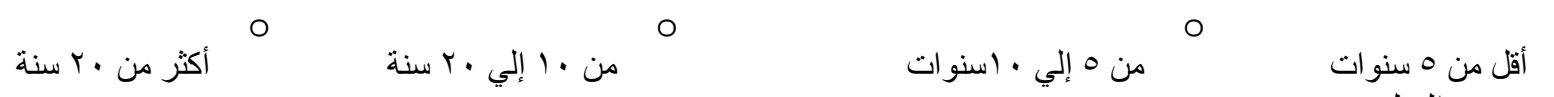

$$
\begin{aligned}
& \text { ب-مستوي التعليم : } \\
& \text { كثور اة } \\
& \text { ماجيستير } \\
& \text { كالوريوس }
\end{aligned}
$$

\section{مصدر معلوماتلك عن العمارة الايناميكية}

1 ـ هل سبق للك درست محتوي عن العمارة الديناميكية أثناء فترة الدر اسة الجامعية :

$$
\mathrm{V}
$$

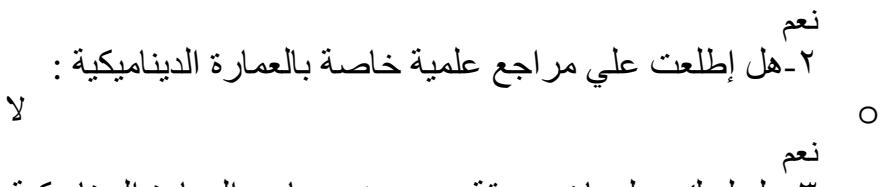
y

ـ ـ هل لديك معلومات مسبقة عن بعض معايير العمارة الديناميكية : V

من وجهة نظرك ما هي نسب أهمية الإعتبارات الواجب توافرها في التصميم الايناميكي كلاً بالنسبة للأخر :

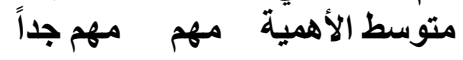

$\begin{array}{lll}0 & 0 & 0 \\ 0 & 0 & 0 \\ 0 & 0 & 0 \\ 0 & 0 & 0 \\ 0 & 0 & 0 \\ 0 & 0 & 0 \\ 0 & 0 & 0\end{array}$

متوسط الأهمية مهم مهم جداً

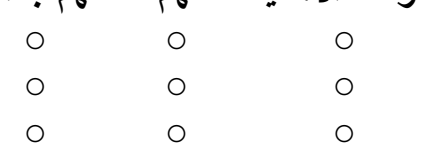

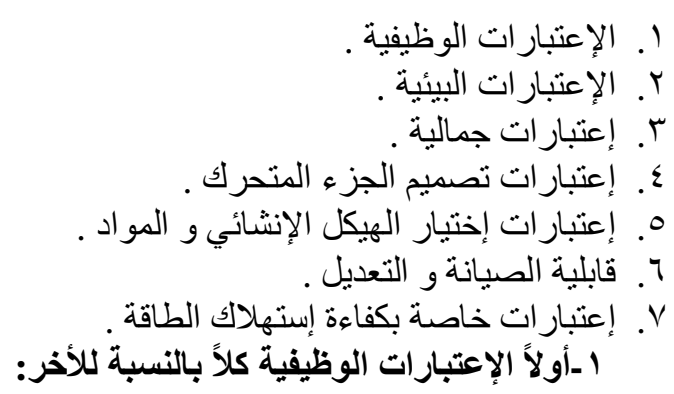

1. أهية إختبار الموقع

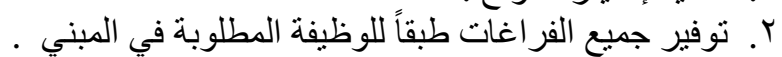

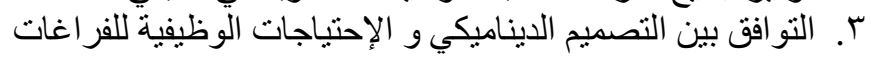




\begin{tabular}{|c|c|c|}
\hline 0 & 0 & 0 \\
\hline 0 & 0 & 0 \\
\hline 0 & 0 & 0 \\
\hline 0 & 0 & 0 \\
\hline مهم جداً & مهم & وسط الأهمية \\
\hline 0 & 0 & 0 \\
\hline 0 & 0 & 0 \\
\hline 0 & 0 & 0 \\
\hline مهم جداً & مهم & متوسط الأهمية \\
\hline 0 & 0 & 0 \\
\hline 0 & 0 & 0 \\
\hline 0 & 0 & 0 \\
\hline O & 0 & 0 \\
\hline
\end{tabular}

متوسط الأهمية مهم

$\begin{array}{lll}0 & 0 & 0 \\ 0 & 0 & 0 \\ 0 & 0 & 0 \\ 0 & 0 & 0\end{array}$

متوسط الأهمية مهم مهم جداً

$\begin{array}{lll}0 & 0 & 0 \\ 0 & 0 & 0\end{array}$

متوسط الأهمية مهم مهم جذاً

$0 \quad 0$

$\circ \quad 0$

متوسط الأهمية مهم مهم جداً

\begin{tabular}{ccc}
0 & 0 \\
0 & 0 & 0 \\
0 & 0 & 0 \\
0 & 0 & 0 \\
0 & 0 & 0 \\
\hline & 0 & 0
\end{tabular}

ع. العلاقة بين الجزء الثابت و المتحركة و عدم إعاقة أي منهما وظيفة الأخر . المعة

ه. دراسة عناصر الحركة الأفقية و الرأسية و ملائمتها مع الحركة في

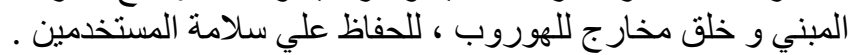

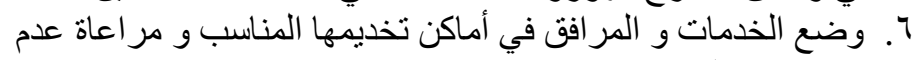
تكر ار ها و تداخل مسار اتها . V. تطبيق التصميم الديناميكي للوائح و القوانين و التشريعات طبقاً لمكان

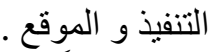
r بـثانياً الإعتبار اتع البيئية كلاً بالنسبة للأخر:

$$
\begin{aligned}
& \text { ا ـ كفاءة التهوية الطبيعية . كفاءة الطية }
\end{aligned}
$$

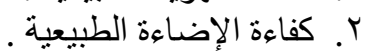

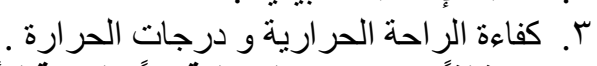

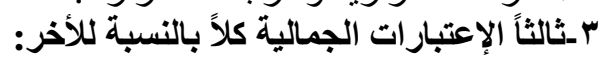

$$
\begin{aligned}
& \text { ا ـ إختيار الثكل الكتلي للمبني ككل . }
\end{aligned}
$$

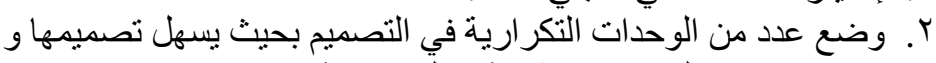

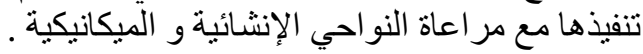

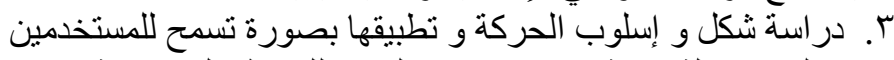

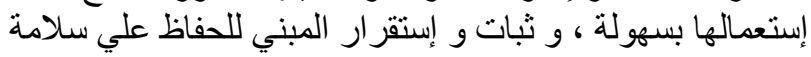

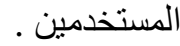

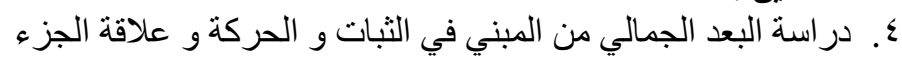

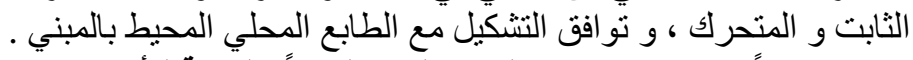

$$
\begin{aligned}
& \text { ع -رابعاً إعتبار ات تصميم الجزء المتحرك كلو كلاً بالنسبة للأخر: }
\end{aligned}
$$$$
\text { 1. موضع الحركة ( العناصر المائية ، الأسقف و التغطيات لأرضيات ، }
$$

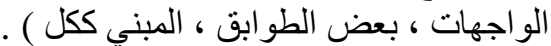

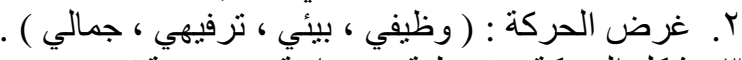

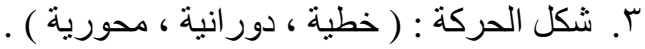
ع. نوع المحرك : ( بدوي ، كهربائي ، هيدروليكي ، دورية ) .

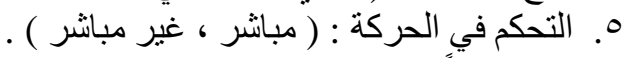
هـخامساً إعتبار ات إختيار الهيكل الإثشائي و المواد كلاً بالنسبة للأخر:

$$
\text { r. . فر اغات متحركة أو فر اغية . }
$$$$
\text { T-سادساً قابلية الصيانة و التعديل كلاً بالنسبة للأخر : }
$$

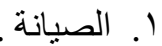

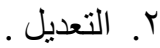
V-سابعاً إعتبار ات خاصة بكفاعة إستهلاك الطاقة كلاً بالنسبة للأخر : Vل
}

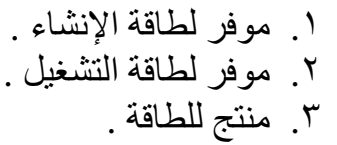

